\title{
SOCIAL FUNCTIONS IN THE SOCIOLINGUISTIC TYPOLOGY (ON THE MATERIAL OF THE LANGUAGES OF THE RUSSIAN FEDERATION)
}

\author{
Vida Yu. Mikhalchenko ${ }^{1}$, Elena A. Kondrashkina ${ }^{2}$, Svetlana V. Kirilenko ${ }^{3 *}$ \\ ${ }^{1}$ Prof. Dr., Head Scientific Researcher, Institute of Linguistics, Russian Academy of Sciences, \\ RUSSIA, vida-mi@mail.ru \\ ${ }^{2}$ Senior Scientific Researcher, Candidate of Sciences (Philology), Institute of Linguistics, Russian \\ Academy of Sciences, RUSSIA, e.kondrashkina@inbox.ru \\ ${ }^{3}$ Scientific Researcher, Candidate of Sciences (Philology), Institute of Linguistics, Russian \\ Academy of Sciences; Assoc. Prof., RUSSIA, svetlanavk@inbox.ru \\ ${ }^{*}$ Corresponding Author
}

\begin{abstract}
The article describes the current state of social linguistics in Russia, its achievements and promising areas for further development. What seems obvious is a relatively small number of scientific works that focus on the methods and techniques of sociolinguistic research and works on typology, including the question of the principles of creating a typological classification of languages. An attempt to create such a classification was presented in a six-volume international work on the languages of the peoples of the world (published in Canada 2000, 2003, Quebec, Laval University). However, this work was not completed and was limited only to an inventory of the social functions of a number of world languages.

The article proposes to develop the principles of a functional classification based on the material of the languages of Russia. For this purpose, the descriptions of social functions in the Canadian-Russian work, the encyclopaedia 'Language and Society' will be used, as well as data from sociolinguistic studies of the languages of Russia. Social functions can be measured using the method of calculating the demographic and communicative power of languages. The authors believe that the development of such a classification, its scientific basis will lead not only to the development of sociolinguistics, but can also become a prerequisite for its further progress.

The paper analyzes the principles of identifying the functional types of languages, considers the integral and differential features of different groups, identified on the basis of the social functions of the languages of Russia. The authors distinguish seven functional types, starting with a language with global social functions (Russian), and ending with the languages of temporary linguistic communities (migrants and migrant laborers).

At the same time, the authors consider the social functions of the Russian language in different linguistic communities, including communities situated outside the territory of Russia. The languages of the second functional type are further analyzed, such as Tatar language, Tuvinian language, Chuvash language, Bashkir language, Yakut language, languages of minorities and languages of migrants.

In conclusion, a description of the multi-component socio-communicative system of the Russian Federation is given and it is concluded that the basic principles of the classification of Russian languages can be used to analyse the linguistic diversity in other regions of the world.
\end{abstract}

Keywords: sociolinguistics, functional typology, demographic capacity, functional capacity, types of languages, Russian language, national languages. 


\section{INTRODUCTION}

The state of the art of any scientific discipline is determined by the development of its theory, conceptual apparatus, methods and techniques, as well as the availability of information about this branch of science.

Modern Russian social linguistics has achieved significant results: plenty of works have been created on the functioning of languages in different regions of the Russian Federation, new scripts are being created for previously unwritten languages. There have appeared sociolinguistic encyclopaedias, materials on the functioning and interaction of languages that are included in various linguistic works. Social linguistics has been introduced into university education as a separate subject, textbooks for universities have been created. At the same time, there are still few generalizing studies, there are almost no works on sociolinguistic typology, generalizing works on the methods and techniques of sociolinguistic research. However, sociolinguistics, like other sciences, in the modern period in the field of research procedures and methods, has risen to a new level: it widely uses accurate methods for assessing sociolinguistic data, computer questionnaires, and the creation of databases. One of the relatively new methods of interpreting sociolinguistic data is the method of creating a 'sociolinguistic portrait', the formation of which involves the presentation in the description of all the main, relevant factors influencing the functional development of a language, as well as a quantitative assessment of the totality of social functions of the studied language. It is quite obvious that in such cases it is not only the scope of functions performed among speakers of the studied language that is important. The frequency of use of this or that function among native speakers is also very important. So, for example, not only the quantitative parameters of mass communication in a particular language are crucial (circulation of newspapers, magazines, the number of hours on radio and television), but also the intensity of the involvement of different social groups in one or another sphere of communication. Only the intensive functioning of a language among the corresponding linguistic community can contribute to its support and development.

It is necessary to investigate the specific mechanisms of the dynamics of the expansion or contraction of the social functions of the languages of Russia at the present stage. In modern studies, authors often talk of the language shift in the dynamics of the social functions of the languages of Russia, which is understood as the decrease of the social functions in languages. Apparently, in fact, the situation is somewhat different, more complicated than it is shown in the modern scientific literature. Most likely, there is neither shrinking in social functions, nor a uniform progressive expansion in them. Apparently, in some spheres of communication, positive dynamics is possible, and in other spheres of communication negative dynamics is highly likely. If we take into account that both the former and the latter refer to the spheres of communication in the same language, then it becomes obvious that, evaluating the general trend of dynamics, one cannot speak only of a negative language shift or only a positive development.

\section{RESEARCH FRAMEWORK}

The following points become crucial for further research:

1) Typological classification of languages according to their social functions;

2) The allocation of functional dominants, that is, the main, most important spheres of communication that are relevant for a given linguistic community and its socio-communicative system.

It is quite obvious that the functional classification of languages is one of the most important tasks of social linguistics, since the relationship between language and society is its main subject. Another thing is also obvious, i.e. the creation of such a classification is impossible without the accumulation of a significant number of private studies of individual languages. It should be noted that in modern Russian sociolinguistics there are many such studies, however, they are fragmentary, not comparable, since each researcher comes to their own, original solution to the problem while conducting a study. Another difficulty in creating a functional classification is the constant expansion or contraction of the social functions of languages, therefore, when classifying languages, it is necessary to have the same reference point - the same period of their functioning. It should be noted that the descriptive work of the social functions of the languages of the Russian Federation was carried out in a two-volume Canadian-Russian work 'Written languages of the world. Languages of the Russian Federation. Sociolinguistic Encyclopedia' (2001-2003). The next logical step forward should be the creation of a sociolinguistic, functional classification of languages.

It should be noted that in the most general form, two indicators help to measure social functions: the demographic power and the functional power of the language. The demographic power of a language is understood as the number of speakers of this language in relation to the total population of the studied area. I would like to clarify this definition: the specifics of the Russian Federation, where a number of peoples have 
lost competence in their native language, makes us believe that the demographic power of a language should be measured in a slightly different way: the demographic power of a language is the number of those who speak a given language in relation to the entire number of people in the linguistic community of a given language. For the peoples of Russia, it is important to define how many people of a particular nationality speak and use their native language. Moreover, it is very dangerous to try to start promotion of a language that has been declared the state language but is not spoken in the entire linguistic community, onto strangers, outsiders, and other linguistic communities. This can lead to a language conflict.

Of course, when it comes to languages that have received the status of state languages, this problem is acute, since it is necessary to expand these languages onto other language communities. However, in our opinion, this process should be preceded by a period of promotion of this language in its own linguistic community. In addition, the time period required to spread the new state language to other linguistic communities can take decades.

Another quantitative indicator is the functional power of the language, which shows the ratio of the spheres of communication in which a particular language is used, with all spheres of communication, with the totality of spheres of communication characteristic of a given linguistic community. The most important sphere of organized communication for national languages is the sphere of verbal national culture. It can be considered that the national language has no competitors here, since it is the national language, which was formed along with the national culture. This language serves this sphere most effectively. So, for example, the texts of the verbal culture, when transmitted by means of another national language, need means of adaptation, i.e. the development of culture-specific words.

Thus, the main relevant features of the functional language type are:

- The presence of a linguistic community (large, medium or small), speaking this language;

- The demographic power of the language;

- The functional power of the language of a given linguistic community;

- The functioning of this language in the dominant spheres of communication;

- Tendencies of functioning - expansion or contraction of functions.

The functional type occupies a place corresponding to the volume of its social functions in the sociocommunicative system of the macro- or micro-linguistic community and is with other components of the socio-communicative system in the relationship of functional complementarity. The following functional types of Russian languages can be distinguished:

Type I. The language with global social functions is Russian.

Il type. Functionally developed languages (Tatar, Chuvash, Bashkir).

III type. Moderately developed languages (Altai, Buryat, Komi-Zyryan, Udmurt, Avar, Kumyk).

IV type. Languages with narrowed social functions (Tsakhur, Karelian, Kalmyk).

$V$ type. Languages with minimal social functions (languages of small peoples).

VI type. Languages with isolated social functions (external and internal diasporas).

VII type. Languages of temporary linguistic communities (migrant workers).

According to the ideas prevailing in the domestic tradition, the world language is characterized by 1) the globality of distribution, 2) its recognition as a capacious and accessible source of human knowledge, 3 ) linguistic features - a reflection of the highest level of production of science, technology, culture achieved by its speakers, and the role of language in the life of the whole world. The richness of the vocabulary, the presence of a linguistic tradition, a system of functional styles, and other linguistic characteristics are also important.

As you know, the Russian language meets all these parameters, therefore it is one of the world languages, languages of international communication. In this regard, its social functions cover a significant number of spheres of communication and, accordingly, social functions. So, the repertoire of social functions of the Russian language in different linguistic communities should include:

- The function of the language of international communication,

- The function of the state language of the Russian Federation, 
- The function of the state language in the republics of the Russian Federation,

- The function of the language of interethnic communication,

- The function of the ethnic language of the Russian people,

- The function of the language of the Russian-speaking diasporas,

- Function of the language of foreign language diasporas.

These social functions are realized with different intensities in different countries of the world, in different social conditions in which social communities live, including the Russian language in the sphere of speech activity. Thus, the functioning of the Russian language in the modern world is determined by the presence of the corresponding linguistic communities. In addition, the Russian language performs a number of other social functions, for example, the function of the language of science, the language of acquaintance with another culture, and the language of business communication. These social functions are less dependent on the territorial distribution of linguistic communities, since people of different nationalities and different social groups are included in their implementation.

It is quite obvious that the study and use of the Russian language differs in the countries of the near (new) abroad and in the countries of the far abroad. In the countries of the new abroad, in our opinion, every cultured person should be fluent in at least three languages: the national state language, Russian and, finally, English, in which a large amount of scientific, technical, economic and other information is now published. The functioning of the Russian language in the new foreign countries is often difficult because of the laws on languages, which, contrary to the trends in the development of the world linguistic process, are monolingual, which generates open and latent language conflicts. The normative legal acts on language policy adopted in many former Soviet republics contradict the 1966 Hague and 1998 Oslo Recommendations on the linguistic and educational rights of national minorities, the European Charter for Regional Languages, the International Covenant on Civil and Political Rights, the Framework Convention on protection of national minorities and other international documents.

In non-CIS countries, at present, in most cases, there is a departure from the study and use of the Russian language. If earlier, before the collapse of the Soviet Union, about 150 million people studied the Russian language in these countries on an on-going basis, today this number has decreased by five times. The Russian-language information space in these countries is shrinking, which negatively affects the possibilities of economic, scientific and cultural cooperation. At the same time, new trends are emerging in the processes of the spread of the Russian language, a kind of reorientation, more and more often the study of the Russian language is motivated by the requirements of the market, and not only by the desire to get acquainted with Russian culture.

The functioning of the Russian language in the modern world has not been sufficiently studied. In addition to the reports of the Ministry of Foreign Affairs on the Russian language in the modern world and books based on the materials of these reports, there are only fragmentary specific sociolinguistic studies on individual problems.

The materials are often mosaic, cannot be compared and generalized, since the research is made using different methods. At the same time, the mentioned works often do not differentiate between the individual functions of the Russian language, there is no unified approach to studying the state of the Russian language in different countries. Such limited comparability of different materials somewhat reduces the possibility of their use for scientific and scientific-practical purposes. Nevertheless, the processes of the functioning of the Russian language in the field of education are shown quite well, therefore, judging mainly by the data of this sphere, it becomes obvious that in a number of countries the Russian language retains its positions and even expands them (for example, in Armenia, in Vietnam, in Mongolia, Spain, Kazakhstan); in other countries (for example, Hungary, Bosnia, Herzegovina, Germany) its functioning is reduced. It is quite obvious that teaching the Russian language is a very important link in its development, since the language competence that is formed in the learning process makes it possible to use a particular language in various spheres of organized and spontaneous (unorganized) communication. However, an equally important factor is the social perspective, that is, the social need to use the knowledge of the world language in the activities of different social groups.

Functionally developed languages (Tatar, Tuvinian, Chuvash, Bashkir, Yakut) belong to type II. This functional type is characterized by the presence of a linguistic community living relatively compactly in one of the republics that speaks and uses this language. An important distinctive feature of this functional type is the state status of languages, the presence of programs for their development. Naturally, this creates more 
convenient conditions for their successful development. The languages of this functional type have a rather high demographic power of the language, since the majority of the linguistic community usually speaks this language. Another important relevant feature is their relatively widespread use in dominant spheres, that is, in spheres of verbal culture. Some languages, for example, Tatar, Bashkir, are used in the field of education, including higher education in some specializations. The trend of functioning should be considered, despite the uneven development of different spheres of communication, the expansion of the social functions of the language. Tatar and Chuvash languages can be cited as an example. Other functional types in terms of the breadth of social functions are located between I and V functional types.

The languages of indigenous peoples are languages with minimal social functions. It should be noted that they are functionally different: among them there are languages that are used only in unregulated communication (Yukaghir, Akhvakh, Taz, Nenets), other languages function minimally in the areas of organized communication (Vepsian, Rutul, etc.), and third languages are used in different spheres is relatively wide, for example, Abaza.

In recent decades, the problem of the functioning of languages in temporary linguistic communities of migrant migrant workers has become relevant. The widespread use of migrant labor in Russia makes the problem of their knowledge of the Russian language urgent. It is especially important to take into account the fact that during the period of perestroika due to the collapse of the Soviet Union, the formation of a number of new sovereign states and the shift in emphasis to new state languages, attention to the study of the Russian language decreased. The consequence of these processes was a decrease in language competence. Apparently, in the future, after the end or weakening of the crisis phenomena, when the issues of labor migration will again become relevant, measures will be taken to organize the impact on this area of the functioning of languages.

Different functional types of languages are included in various socio-communicative systems as its components. Socio-communicative systems serve different linguistic communities. In world linguistic practice, one-component socio-communicative systems (Iceland), two-component socio-communicative systems (Canada, Finland), multicomponent (Switzerland, Singapore) are observed.

\section{CONCLUSION}

A multicomponent socio-communicative system operates in the Russian Federation: 34 languages have legal status. The language of the entire multinational community of the Russian Federation is the state language of Russia - Russian. In 22 national republics, it co-functions with the republican state languages. In the national republics of the Russian Federation, there are different types of social and communication systems: two-component, for example, Tuva, Tatarstan, Bashkortostan, Mordovia, Udmurtia, threecomponent, for example, Mari El, Mordovia, and multicomponent, for example, Dagestan. In the regions inhabited by Russians, a one-component socio-communicative system functions, that is, different forms of the existence of the Russian language. Among the linguistic diversity of the Russian Federation, in which scientists count from 100 to 180 languages, 7 functional types can be distinguished, this can form the basis of the sociolinguistic classification of the languages of Russia. The basic principles of this classification can be applied to the interpretation of linguistic diversity in other regions of the world.

\section{ACKNOWLEDGEMENT}

The reported study was funded by RFBR and DFG, project number № 21-512-12002 HHИO_a "Prognostic methods and future scenarios in language policy - multilingual Russia as an example"

\section{REFERENCE LIST}

Dictionary of Sociolinguistic Terms (2006). / Mikhalchenko, V.Yu. (ed.) Moscow: Institute of Linguistics, Russian Academy of Sciences.

Language and society. Encyclopaedia. Moscow (2016) 872 c. ISBN 978-5-91172-129-9

Mikhalchenko, V.Yu., Kozhemyakina, V.A. (2016) Methods of sociolinguistic research // Language and society. Encyclopedia. Moscow. pp 282-285.

Mikhalchenko, V.Yu. (2016) Language situation and language policy in modern Russia // Language and society. Encyclopaedia. Moscow. pp 5-16. 
Proceedings of SOCIOINT 2021 8th International Conference on Education and Education of Social Sciences 14-15 June, 2021

Written languages of the world. Languages of the Russian Federation (2000). Book 1. Moscow. Written languages of the world. Languages of the Russian Federation (2003). Book 2. Moscow. Yunus D. Desheriev (1976) Social Linguistics: to the foundations of the general theory. Moscow. 